\title{
Use of Preexpanded Forehead and Neck Skin in Case of Giant Facial Hairy Naevus: Planning and Technique
}

\author{
${ }^{1}$ Department of Burns, Plastic \& Reconstructive Surgery, PGIMER \& \\ DR. R.M.L. Hospital, New Delhi, India \\ 2Department of Plastic Surgery, Lady Hardinge Medical College and \\ Associated Hospital, New Delhi, India \\ ${ }^{3}$ Department of Burns, Plastic \& Reconstructive Surgery, VMMC \& \\ Safdarjung Hospital, New Delhi, India \\ Indian J Plast Surg 2021;54:221-224.
}

Mukesh Kumar Sharma ${ }^{1}$ Naveen Kumar ${ }^{2} \quad$ V. Suman Babu ${ }^{1}$ Vinay Kumar Tiwari ${ }^{3}$

Address for correspondence Naveen Kumar, MS, MCh, Department of Plastic Surgery, Lady Hardinge Medical College and Associated Hospital, New Delhi 110001, India (e-mail: drnaveenvmmc@gmail.com).

\begin{abstract}
A congenital nevi is a pigmented patch which requires complete surgical excision for cosmetic reasons. Here, we report a case of a patient with facial hairy pigmented lesion, occupying the right half of her face since birth, who underwent complete surgical excision and staged reconstruction utilizing, preexpanded forehead and neck skin. We used two rectangular tissue expanders with 150 and 300 cubic $\mathrm{cm}$ of volumes inserted in the forehead and the neck, respectively. The length of the expanders selected were equal to 1.2 to 1.5 times the length of their respective lesions, whereas

Keywords

- congenital

- nevi

- expander the width of the base of the expanders were approximately similar to the width of their defects. It is concluded with this case report that tissue expansion provides a good cosmetic and anatomical correction to cover large defects, with adjacent skin having similar properties.
\end{abstract}

\section{Introduction}

The giant congenital melanocytic nevi is defined as a lesion affecting $2 \%$ of total body surface area (TBSA) in newborns and toddlers, or having a diameter larger than $20 \mathrm{~cm}$ in older children and teenagers. ${ }^{1}$ The incidence varies from 1 in 100 births for small nevi to 6 in 1000 births for medium nevi to $1 / 500,000$ newborns for giant nevi. ${ }^{2}$ A variety of surgical and nonsurgical options exist for the management of such cases. Complete surgical excision of congenital nevi is done for cosmetic reasons. ${ }^{3}$ The risk of developing a cancer during the lifetime of the patient remains low even in the residual nevus. Therefore, during treatment decision, factors such as satisfactory cosmetic outcome and psychological effect should be taken into consideration. ${ }^{4}$

We report here a case of a patient with hairy lesion who underwent complete surgical excision and staged reconstruction.

published online

November 30, 2020
DOI https://doi.org/ 10.1055/s-0040-1721537 ISSN 0970-0358.

\section{Methods}

\section{Case Presentation}

An 18-year-old unmarried girl presented with pigmented patch occupying the right half of her face since birth $(-$ Fig. 1), which was associated with pruritus, skin fragility, erosion, and decreased sweating. On examination, she had a hairy gray black pigmented lesion involving the right side of the face, extending superiorly from right frontotemporal hairline to the lower border of the mandible inferiorly, medially reaching up to lateral nasal wall and nasolabial crease, and laterally up to preauricular crease involving right eyebrow and whole of cheek.

The total dimension of the nevus was around $16 \times 7 \mathrm{~cm}$ and the lesion was divided into two parts, that is, one above the zygomatic arch with surface area $35 \mathrm{sq} \mathrm{cm}(7 \times 5 \mathrm{~cm})$ and second below the arch with surface area $63 \mathrm{sq} \mathrm{cm}(9 \times 7 \mathrm{~cm})$. Thereafter, we selected the two rectangular tissue expanders: one with base

\footnotetext{
(C) 2020. Association of Plastic Surgeons of India.

This is an open access article published by Thieme under the terms of the Creative Commons Attribution-NonDerivative-NonCommercial-License, permitting copying and reproduction so long as the original work is given appropriate credit. Contents may not be used for commercial purposes, or adapted, remixed, transformed or built upon. (https://creativecommons.org/licenses/by-nc-nd/4.0/)

Thieme Medical and Scientific Publishers Pvt. Ltd. A-12, 2nd Floor, Sector 2, Noida-201301 UP, India
} 
area of $44 \mathrm{sq} \mathrm{cm}(11 \times 4 \mathrm{~cm})$ for forehead region to resurface the lesion above the zygomatic arch, and the second one with the base area of $66 \mathrm{sq} \mathrm{cm}(11 \times 6 \mathrm{~cm})$ for the second part. The length of the expanders selected were equal to 1.2 to 1.5 times the length of their respective lesions, whereas the width of the base of the expanders were approximately similar to the width of their defects. Now to calculate the volume and height of the expanders selected, we used the Microsoft Excel spreadsheet method $^{5}$ that gave us the results as approximately 100 cubic cm as volume and nearly $2.5 \mathrm{~cm}$ as height for the expander in forehead and 225 cubic $\mathrm{cm}$ and $3.5 \mathrm{~cm}$ as volume and height, respectively, for the expander in the neck. Therefore, we selected the final expanders having volume and height as 150 cubic $\mathrm{cm}$ and $4 \mathrm{~cm}$, respectively, for the first expander and as 300 cubic $\mathrm{cm}$ and $6 \mathrm{~cm}$, respectively, for the second one.

During the first surgery, a rectangular tissue expander of size $110 \times 40 \times 40 \mathrm{~mm}$ was inserted in the forehead through the frontotemporal hairline with port in the temporal region, whereas second tissue expander of size $110 \times 60 \times 60 \mathrm{~mm}$ was inserted in the neck area with port in the mastoid region (-Fig. 2). The expanders were inflated with once a weekly regime. The expander in the forehead region was expanded to approximately $220 \mathrm{~mL}$ and the second one in the neck was expanded to approximately $400 \mathrm{~mL}$. Thus, the expanders were expanded to approximately $40 \%$ of their initial volumes. For rotation advancement, the flap roughly corresponded to

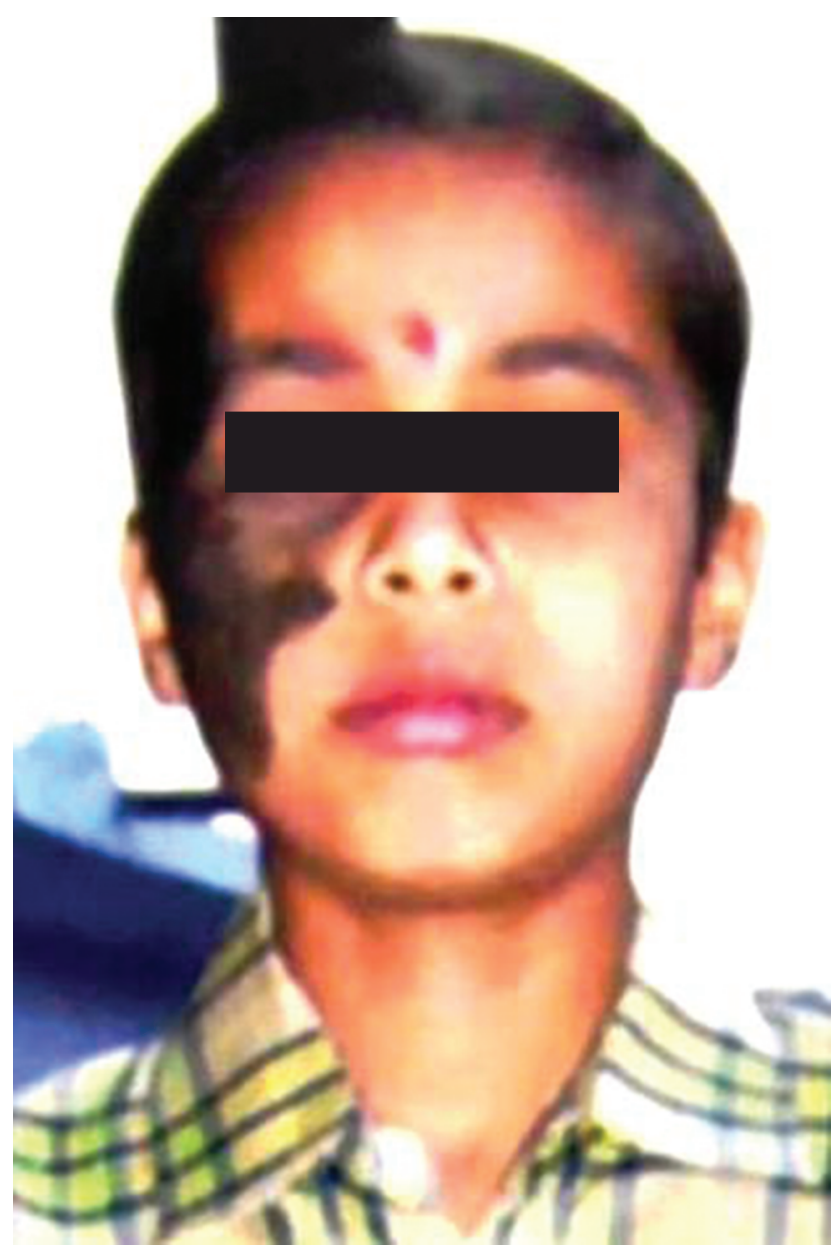

Fig. 1 Image of the same patient at 10 years of age. the defect length below zygomatic arch plus expander base width (approximately $15 \mathrm{~cm}$ ), which is approximately equal to the length of the dome of the inflated expander, that is, height gained + length of expander which is $17 \mathrm{~cm}$. For propeller flap, defect width $=$ propeller flap width, defect length $=$ or $<$ propeller flap length.

After 3 months of expansion, full-thickness skin excision of the nevus was done. The expanders were removed and the first part of the nevus was replaced by a propeller flap, based on the anterior branch of the right superficial temporal artery, and lower part by a flap which was rotated and advanced from the preexpanded skin over the neck, with pivot point around the angle of right mandible ( - Fig. 3). Postoperatively, venous congestion was seen over both the flaps, which had resolved spontaneously over the period of the following 3 to 4 days ( - Fig. 4). The postoperative period was uneventful, and the suction drains were removed on the 7th day.

After 3 months of second surgery, the excision of residual nevus around eyebrow and nasolabial crease was done under local anesthesia. Cheek flap and forehead flap advancement and readjustment were done (-Fig. 5). Minor refinements like medial scar $\mathrm{Z}$ plasty to correct the deformity of the

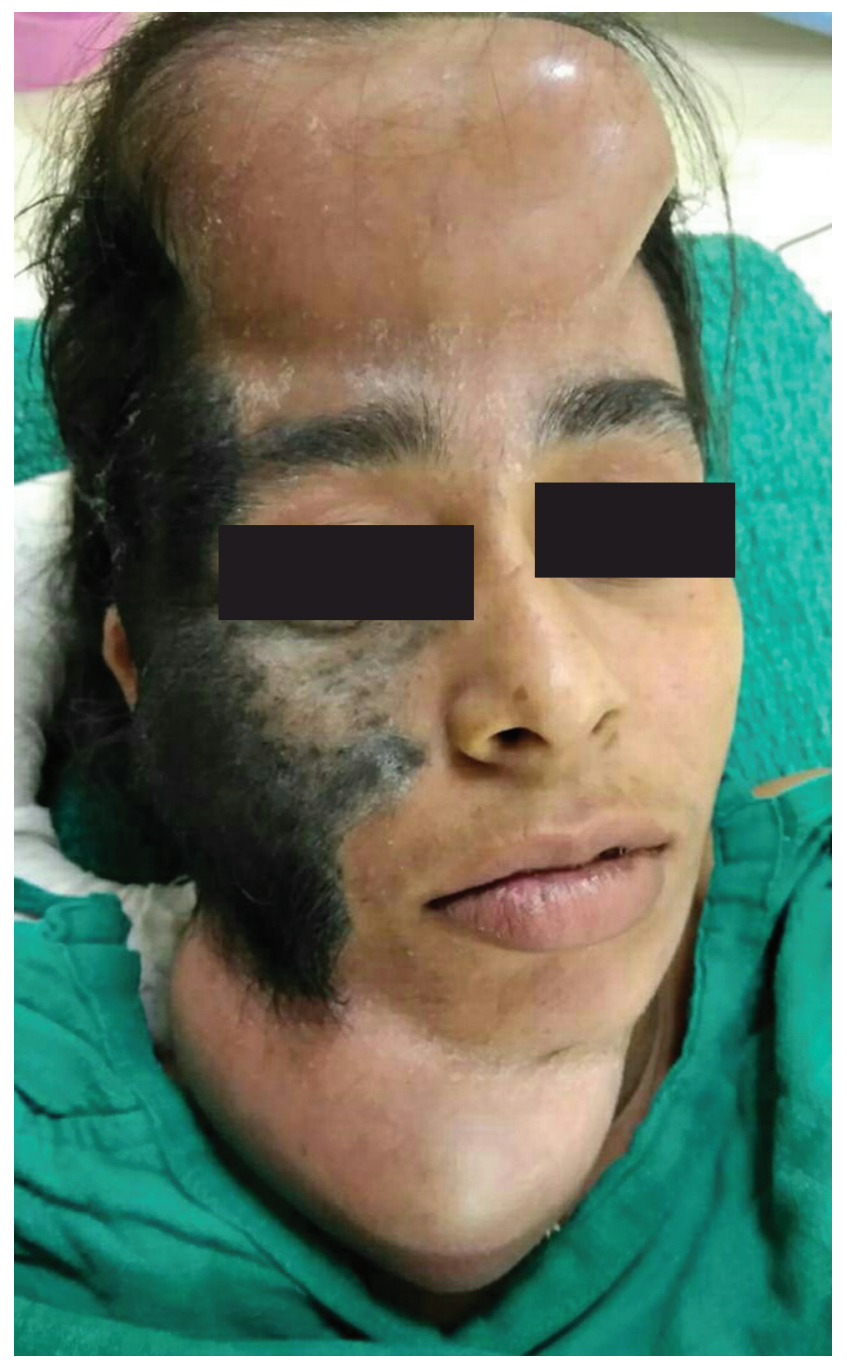

Fig. 2 Image of large right side facial hairy nevus of the patient, with tissue expanders inserted inside for head and neck (front view). 


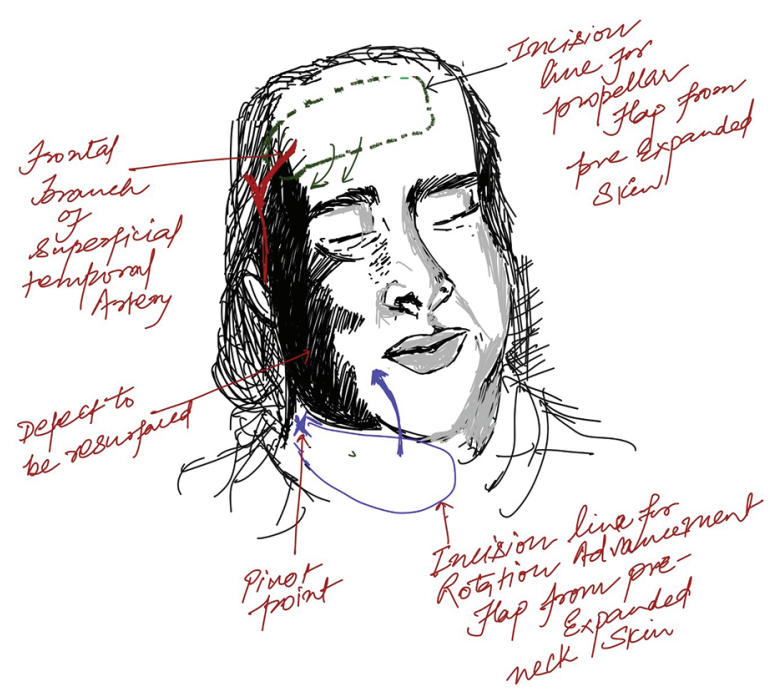

Fig. 3 Incision marking for the flaps.

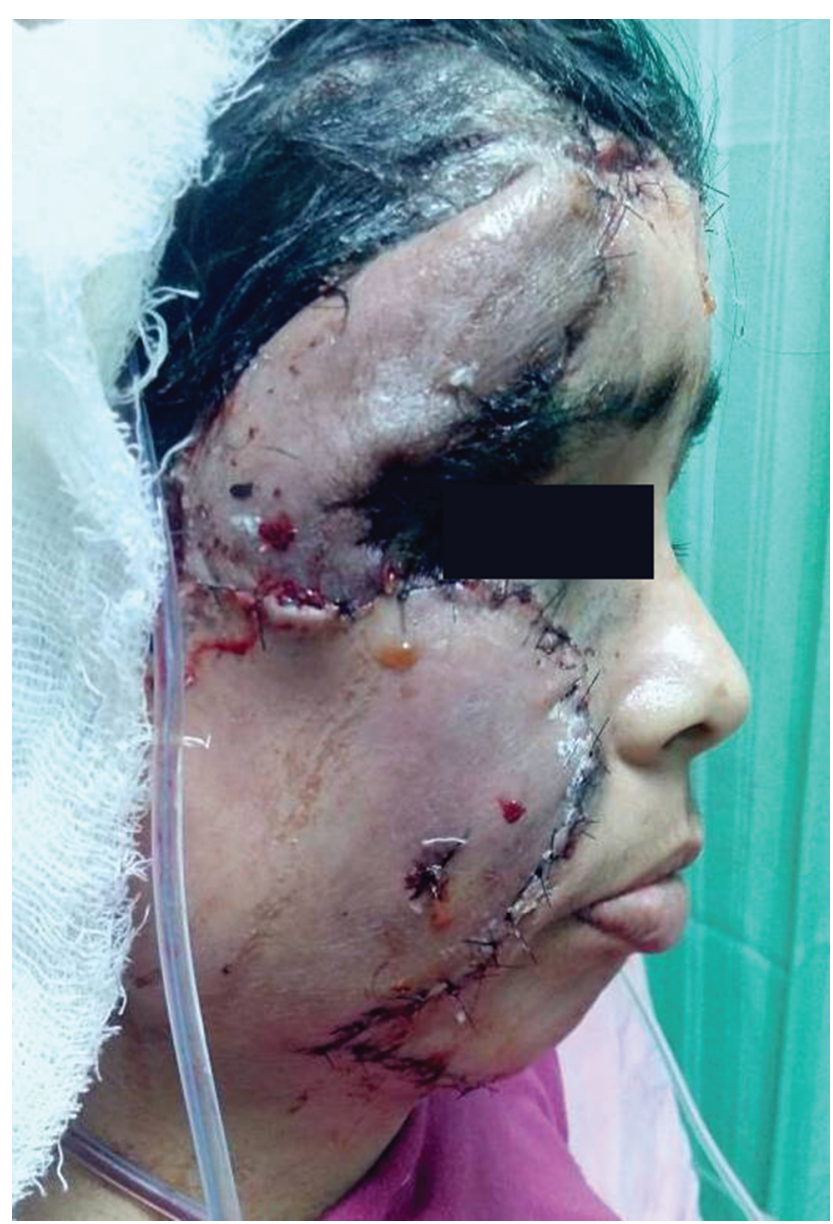

Fig. 4 Postoperative image following second surgery. right side angle of mouth and either scar revision or laser therapy for the patch of hair over the right forehead were planned ( - Fig. 6a, b, c).

\section{Discussion}

Giant congenital melanocytic nevus has traditionally been called birthmark in India and often bears a social stigma. Congenital pigmented nevi are associated with risk of developing malignant melanoma. ${ }^{6}$ The nevus in our report belongs to Group 3 class of giant facial nevi, that is, more than $12 \mathrm{~cm}$ maximum, involving more than two aesthetic units, and requiring more than two reconstructive stages. ${ }^{7}$ Giant nevi are variously defined as those requiring serial excision or tissue expansion or more commonly $>20 \mathrm{~cm}$ in the greatest dimension ${ }^{8}$. Chen ${ }^{9}$ defined giant congenital nevi as covering $1 \%$ of body surface area in the face and neck and $2 \%$ elsewhere on the body. Therefore, in accordance with both the above-mentioned definitions, the lesion in our case report is a giant nevus involving the most of half of the face, which is defined by Lesham et al as being hemifacial (forehead, periocular area, nose, and cheek). ${ }^{10}$

The goal of treatment is complete excision with satisfactory cosmetic reconstruction. ${ }^{4}$ Several therapeutic procedures have been considered. Nonsurgical options include dermabrasion,

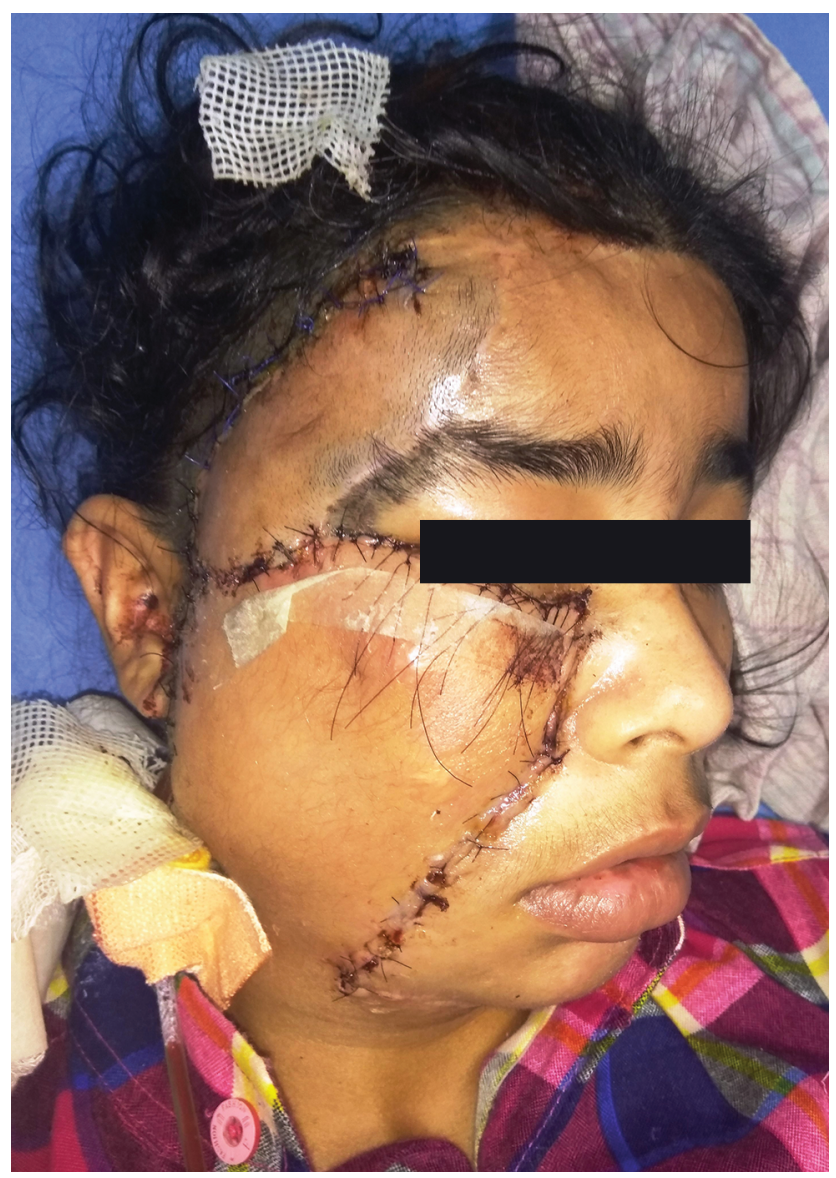

Fig. 5 Postoperative image following third surgery. 

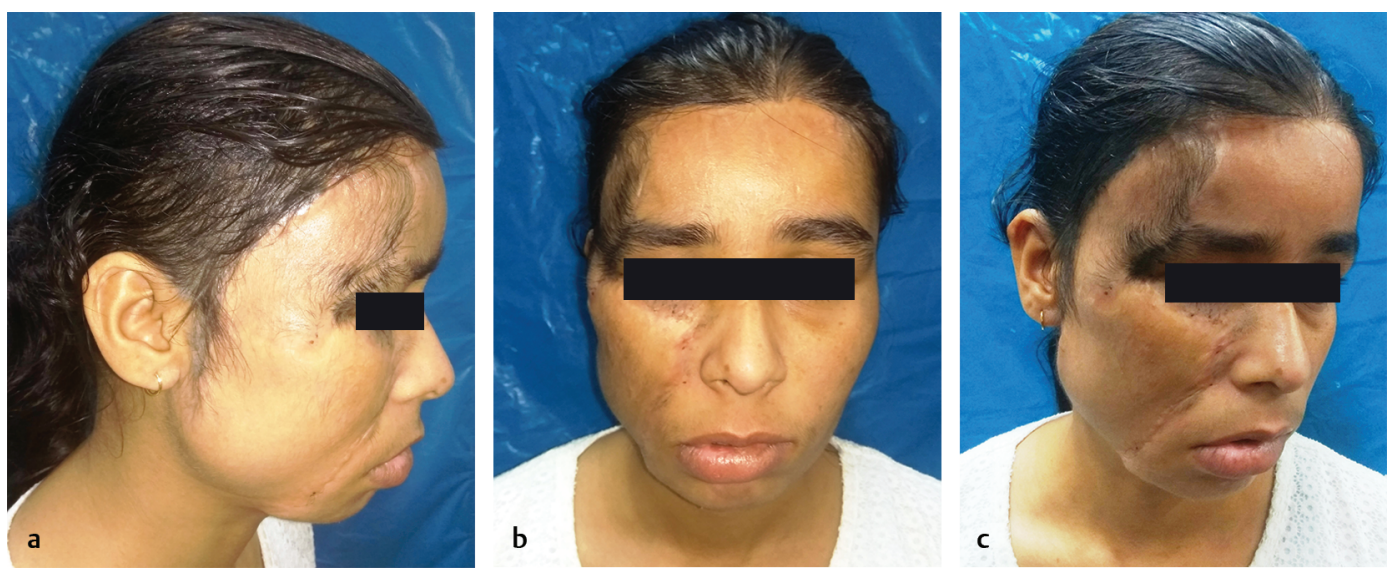

Fig. 6 (a) Follow-up image after 1 year following further refinement (lateral view). (b) Follow-up image after 1 year following further refinement (frontal view). (c) Follow-up image after 1 year following further refinement (oblique view).

laser ablation, curettage, and chemical peel. ${ }^{11}$ Surgical options include staged excision with primary closure, skin graft, local flaps, skin substitute like Integra, ${ }^{12}$ or tissue expansion and flap cover, ${ }^{13}$ or single-stage complete excision and microvascular free flap coverage.

Tissue expansion has become one of the most effective forms of treatment of large and giant nevi, which allows the complete excision of the nevus while maintaining acceptable aesthetic and functional outcomes. The available flap length is estimated by subtracting the base width from the length of the dome of the inflated tissue expander. ${ }^{14}$ However, infection, hematoma, expander exposure, and implant failure are the most common complications of tissue expansion..$^{15}$ Microvascular free flap cover has various disadvantages: requires microsurgical expertise, less tissue match in terms of color and texture, sometimes become bulkier, and flap failure. Tissue expansion has best tissue match, with delayed flap having less chance of congestion and failure. The surface area gain provided by the rectangular expander is usually more as compared with any other expander, which is approximately $38 \%{ }^{16}$. Therefore, we decided to use rectangular-/cuboid-shaped tissue expander. The use of propeller flap and planning of the final suture line were unique in our case, with suture lines falling in the natural creases.

\section{Conclusion}

Management of giant melanocytic nevi requires complete surgical excision with acceptable aesthetic reconstruction. Tissue expansion provides a good cosmetic and anatomical correction to cover such large defects.

\section{Conflicts of Interest}

None declared.

\section{References}

1 Arneja JS, Gosain AK. Giant congenital melanocytic nevi of the trunk and an algorithm for treatment. J Craniofac Surg 2005;16(5):886-893
2 Das SK, M A, Subudhi M. Giant congenital melanocytic nevi: a case report. J Clin Diagn Res 2013;7(1):154-155

3 Viana AC, Gontijo B, Bittencourt FV. Giant congenital melanocytic nevus. An Bras Dermatol 2013;88(6):863-878

4 Marghoob AA. Congenital melanocytic nevi. Evaluation and management. Dermatol Clin 2002;20(4):607-616, viii

5 Agrawal K, Agrawal S. Tissue regeneration during tissue expansion and choosing an expander. Indian J Plast Surg 2012;45(1):7-15

6 Watt AJ, Kotsis SV, Chung KC. Risk of melanoma arising in large congenital melanocytic nevi: a systematic review. Plast Reconstr Surg 2004;113(7):1968-1974

7 Gur E, Zuker RM. Complex facial nevi: a surgical algorithm. Plast Reconstr Surg 2000;106(1):25-35

8 Jensen JN, Gosain AK. Congenital melanocytic nevi. In: Charles HT, Kevin CC, Arun KG, et al. eds. Grabb and Smith's Plastic Surgery. 7th ed. Philadelphia: Wolters Kluwer Health/ Lippincott Williams \& Wilkins; 2013139

9 Giant congenital melanocytic nevi. In: Harold C, ed. Atlas of Genetic Diagnosis and Counseling. New York: Springer; 2017:1227-1236

10 Leshem D, Gur E, Meilik B, Zuker RM. Treatment of congenital facial nevi. J Craniofac Surg 2005;16(5):897-903

11 Mahabbat N, Alohaideb N, Aldaghri F, Alshomer F, Murad MA. Functional subunit reconstruction of giant facial congenital melanocytic nevi in children with the use of matriderm and skin graft: Surgical experience and literature review. Eplasty 2018;18:e30

12 Grunwaldt LJ, Adetayo OA, MacIsaac ZM, Losee JE, Kumar AR. Successful reconstruction of complex pediatric nasal lesions: improving outcomes using dermal regenerative templates. Plast Reconstr Surg Glob Open 2014;2(2):e107

13 Rhodes AR. Melanocytic precursors of cutaneous melanoma. estimated risks and guidelines for management. Med Clin North Am 1986;70(1):3-37

14 Spence RJ. Expanded transposition flap technique for total and subtotal resurfacing of the face and neck. J Burns Wounds 2007;6:e8

15 Manders EK, Schenden MJ, Furrey JA. Hetzler PT, Davis TS, Graham WP III. Soft-tissue expansion: concepts and complications. Plast Reconstr Surg 1984;74(4):493-507

16 van Rappard JHA, Molenaar J, van Doorn K, Sonneveld GJ, Borghouts JMHM. Surface-area increase in tissue expansion. Plast Reconstr Surg 1988;82(5):833-839 